\title{
Study protocol of the quasi-experimental evaluation of "KEIGAAF": a context-based physical activity and nutrition intervention for primary school children
}

S. R. B. Verjans-Janssen ${ }^{1 *}$ (D), Dave H. H. Van Kann², Sanne M. P. L. Gerards', Steven B. Vos ${ }^{2,3}$, Maria W. J. Jansen ${ }^{4,5}$ and Stef P. J. Kremers ${ }^{1}$

\begin{abstract}
Background: The environment affects children's energy balance-related behaviors to a considerable extent. A context-based physical activity and nutrition school- and family-based intervention, named KEIGAAF, is being implemented in low socio-economic neighborhoods in Eindhoven, The Netherlands. The aim of this study was to investigate: 1) the effectiveness of the KEIGAAF intervention on BMI z-score, waist circumference, physical activity, sedentary behavior, nutrition behavior, and physical fitness of primary school children, and 2) the process related to the implementation of the intervention.

Methods: A quasi-experimental, controlled study with eight intervention schools and three control schools was conducted. The KEIGAAF intervention consists of a combined top-down and bottom-up school intervention: a steering committee developed the general KEIGAAF principles (top-down), and in accordance with these principles, KEIGAAF working groups subsequently develop and implement the intervention in their local context (bottom-up). Parents are also invited to participate in a family-based parenting program, i.e., Triple P Lifestyle. Children aged 7 to 10 years old (grades 4 to 6 in the Netherlands) are included in the study. Effect evaluation data is collected at baseline, after one year, and after two years by using a child questionnaire, accelerometers, anthropometry, a physical fitness test, and a parent questionnaire. A mixed methods approach is applied for the process evaluation: quantitative (checklists, questionnaires) and qualitative methods (observations, interviews) are used. To analyze intervention effectiveness, multilevel regression analyses will be conducted. Content analyses will be conducted on the qualitative process data.
\end{abstract}

Discussion: Two important environmental settings, the school environment and the family environment, are simultaneously targeted in the KEIGAAF intervention. The combined top-down and bottom-up approach is expected to make the intervention an effective and sustainable version of the Health Promoting Schools framework. An elaborate process evaluation will be conducted alongside an effect evaluation in which multiple data collection sources (both qualitative and quantitative) are used.

Trial registration: Dutch Trial Register NTR6716 (registration date 27/06/2017, retrospectively registered), METC163027, NL58554.068.16, Fonds NutsOhra project number 101.253.

Keywords: Physical activity, Sedentary behavior, Nutrition, Children, Primary school, Family, Intervention

\footnotetext{
* Correspondence: s.verjans@maastrichtuniversity.nl

${ }^{1}$ Department of Health Promotion, NUTRIM School of Nutrition and

Translational Research in Metabolism, Maastricht University, PO Box 616,

Maastricht, The Netherlands

Full list of author information is available at the end of the article
}

(c) The Author(s). 2018 Open Access This article is distributed under the terms of the Creative Commons Attribution 4.0 International License (http://creativecommons.org/licenses/by/4.0/), which permits unrestricted use, distribution, and reproduction in any medium, provided you give appropriate credit to the original author(s) and the source, provide a link to the Creative Commons license, and indicate if changes were made. The Creative Commons Public Domain Dedication waiver (http://creativecommons.org/publicdomain/zero/1.0/) applies to the data made available in this article, unless otherwise stated. 


\section{Background}

A large number of Dutch children do not meet the national recommendations for physical activity and healthy nutrition behavior. In 2015, less than half of the children (48\%) aged 4 to 12 years were moderately physically active at least 60 min per day, with activities aimed at improving or maintaining physical fitness being done at least two times per week [1]. Moreover, children in the same age category spent on average $7.3 \mathrm{~h}$ per day being sedentary [1, 2]. Compliance with Dutch healthy nutrition guidelines is even lower; for example, only $5 \%$ of children between the ages of 7 and 19 years met the Dutch guidelines for daily fruit consumption (2 pieces a day), and just $1 \%$ met those for vegetable consumption (250 g daily) [3]. Additionally, unhealthy foods are consumed in large quantities. For example, a study on the consumption of sugar-sweetened beverages among a sample of Dutch primary school children from diverse ethnic backgrounds showed a consumption level of 0.91 per day [4]. This study shows that these unhealthy balance-related behaviors are more prevalent among children living in families with a low socio-economic position [5-9].

The environment has a great influence on children's physical activity (PA), sedentary behavior (SB), and nutrition behavior (NB) - referred to jointly as energy balance-related behaviors (EBRBs) [10]. At the microenvironmental level, the family and school environment are important settings that influence children's EBRBs [11], with the child's parents exerting the most important influence on their children's EBRBs [12-17]. For example, parents can affect their child's EBRBs by applying certain parenting practices, like monitoring dietary intake [13]. The physical home environment also stimulates or discourages healthy EBRBs, e.g., by the availability of healthy or unhealthy foods at home [18].

On weekdays, the school environment heavily influences children's PA [19]. The mode of transportation to and from school, physical activity during school recess (playtime), and physical education (PE) add to children's levels of physical activity behavior on a school day [20]. On the other hand, the school environment generally facilitates sedentariness among children, since most educational activities are performed in a seated position [21]. Because the children often consume lunch, beverages, and snacks during school time, schools can also affect the children's nutrition behavior. Even though Dutch primary school children bring their own beverages, snacks, and lunch to school, school nutrition policies (e.g., what children are allowed to bring to school) and healthy nutrition-promoting interventions can stimulate healthy nutrition behavior at school [22, 23].

Initiatives such as The Healthy School have been put in place to change children's health behaviors via schools [24, 25]. In a more traditional approach, interventions are developed by the researchers or health promoters, based on theory and best practices. Subsequently, the interventions are implemented in a relatively top-down fashion: intervention implementers, e.g. school teachers or school staff, are required to adhere to the intervention protocol and implement the intervention as intended with strict fidelity [26]. In such a top-down approach, the complexity of school systems is not taken sufficiently into account [26]. Each school is different, and each context in which the school operates can be considered unique [27]. The effectiveness of a school-based intervention depends on multiple factors within this context, such as the characteristics of the community (e.g. socio-economic status), characteristics of the school staff, school needs and priorities, internal and external collaborations, the school's physical environment, and its resources [27].

In a bottom-up approach, in which an intervention is developed by the users, in this case the schools, these contextual factors are taken into account, resulting in an intervention that meets the local needs and possibilities and is compatible with the school's priorities [28-30]. This, in turn, encourages the school's ownership of the intervention and enhances sustainability in the long-term [26, 28, 31]. A purely bottom-up approach may lead to the adoption and implementation of interventions that lack theoretical or empirical evidence regarding their impact on sustained behavior change [32]. Therefore, in the current project, a combined top-down and bottom-up approach is applied in which a schoolbased physical activity and nutrition intervention is developed and implemented by the school, local professionals, and parents, and guidelines about evidence are provided by a steering committee.

To ensure that not only the child's school environment but also the parents are involved in the intervention, the parents are invited to participate in a family-based lifestyle parenting program. Family-based parenting interventions have proven to be effective in reducing overweight among children and improving their EBRBs $[33,34]$. As it is unclear whether high-risk children benefit enough from school-based interventions targeted at all children $[35,36]$, this part of the project is focused on parents in need of additional support regarding lifestyle-related parenting. This may contribute to the reduction of health inequalities between healthy children and high-risk children [37, 38].

The overall aim of the context-based school- and family-based interventions is to improve the EBRBs of children living in low socio-economic neighborhoods by creating an environment that stimulates healthy EBRBs and discourages unhealthy EBRBs. The intervention, called KEIGAAF ('KEIGAAF' is a Dutch acronym and a 
local term referring to 'super cool'), is based on two promising avenues: a school-based physical activity and nutrition intervention combining a top-down and bottom-up approach [39], and a family-based lifestyle coaching intervention [33]. In this paper, the development and implementation of the KEIGAAF intervention are elaborated. The study design is outlined which evaluates the intervention's effectiveness on the PA behavior, sedentary behavior, nutrition behavior, weight status, and physical fitness of children aged 7 to 10 years living in low socio-economic neighborhoods (Additional file 1). To evaluate whether effects on children's outcome measures are due to the intervention, a quasi-experimental controlled evaluation study will be conducted: the results of an intervention group will be compared with a control group consisting of children attending schools where the KEIGAAF intervention is not implemented.

A process evaluation will be conducted in addition to the effect evaluation. It is essential to look at intervention effectiveness in the context in which the intervention is implemented. An understanding of what is going on locally when implementing the intervention helps to clarify what works in what situation and for whom. This knowledge is essential when transferring effective EBRB-promoting intervention elements in the future to other situations [40]. Therefore, the second aim of this study is to evaluate the implementation of the KEIGAAF intervention (what is implemented and how is it implemented) and how contextual factors influence this implementation.

\section{Methods}

\section{Study design}

The aim of the KEIGAAF project is to design and test the effectiveness of the school- and family-based intervention on the primary outcome measure (BMI z-score) and the secondary outcome measures (PA behavior, sedentary behavior and nutrition behavior, physical fitness, and waist circumference) of children aged 7-10 years living in low socio-economic neighborhoods.

A convenience sample of intervention schools was recruited in Eindhoven, a relatively large city in the southern part of the Netherlands. Schools were eligible if: 1) they were located in a low socio-economic neighborhood; 2) they had no plans to merge with another school or to relocate in the coming three years, and if; 3) the school staff was willing to participate actively in KEIG AAF and to collaborate with parents and local partners, for instance, sports professionals, social workers, and/or municipality officers. The steering committee of the KEIGAAF project, consisting of researchers from Maastricht University and Fontys University of Applied Sciences (School of Sports Studies) and local partners from a school board, a sports support organization, and a social welfare organization, identified nine eligible schools. All nine schools were contacted and informed about the project, and eight schools agreed to participate. Because of the active participation of the intervention schools in the development and implementation of the intervention, no randomization was applied.

Control schools were recruited in Maastricht, a city comparable to Eindhoven based on the level of urbanization and the socio-economic status of the neighborhoods. Three schools agreed to participate in the study; these schools did not apply the KEIGAAF intervention (Fig. 1). Due to the distance between Eindhoven and Maastricht (approximately $90 \mathrm{~km}$ ), a low risk of contamination is expected. KEIGAAF is funded by Fonds NutsOhra, project number 101.253, and the trial is registered as NTR6716. Ethical approval was obtained from the medical ethics committee of the Maastricht University Medical Centre (METC163027, national number: NL58554.068.16).

\section{Participants}

In the Dutch education system, children attend first grade at age 4 . For this study, all children from grades 4 to 6 , thus between the age of 7 and 10 years, of the participating intervention and control schools were eligible for inclusion. The researcher visited the eligible classes of the participating schools and talked to the children about the study. The children were given written information about the study to take home to their parents. In the parental information letter, the parents were informed about this specific information moment. They were also given the opportunity to ask questions about

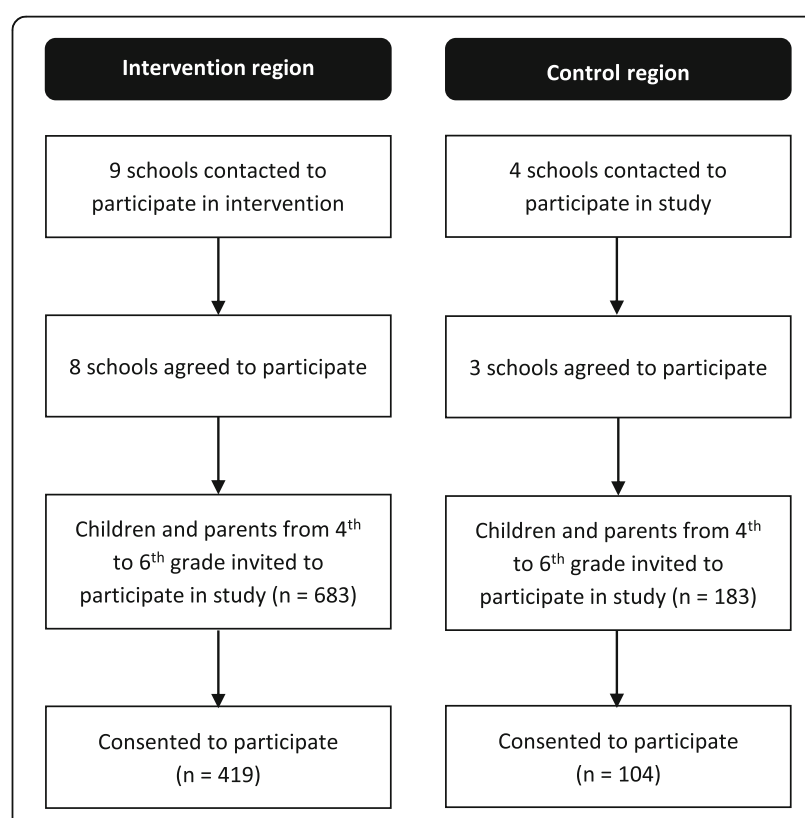

Fig. 1 Study design 
the study of the researcher during planned school meetings. School principals posted a message about the study in the school newsletter and/or on the school website well in advance. Once the parents and the child decided to participate, both parents signed an informed consent. Of the eligible children, $60.4 \%$ (61.3\% in the intervention group and $56.8 \%$ in the control group) consented to participate in the study.

Parents of children who attended schools with relatively high proportions of overweight and obesity as defined during baseline measures (March and April 2017) were invited to participate in Lifestyle Triple $\mathrm{P}$, the family-based parenting program. This strategy was applied to prevent stigmatization. The parents were recruited via written information: a flyer was distributed among the parents, a message was posted in the school newsletter and/or on the school website, and a poster was displayed at the entrance of the school. In addition, the family-based intervention coaches and the school doctor personally recruited parents. The coaches visited the school multiple times before school started and informed the parents about the intervention. The parents who participated in the intervention were given written information about the study related to the intervention. Parents who agreed to participate in this study signed an informed consent.

\section{School-based intervention}

The design of the school intervention follows the combined top-down/bottom-up approach previously successfully applied in the Active Living study (Fig. 2) $[39,41]$. In this mutual adaptation approach [26, 42], a steering committee develops the KEIGAAF principles, and KEIGAAF working groups at school level implement these principles in accordance with the needs of the school and its community. These principles are quite generic; the working groups have the autonomy to make almost all decisions regarding the intervention content. An action-oriented approach is applied: the intervention is continuously developed and adapted according to local needs and current systems. Adapting an intervention to local needs enhances intervention effectiveness [43].

The KEIGAAF principles (see Fig. 3), as developed by the steering committee, are:

1) Each school forms a working group, consisting of school staff, e.g., teachers, the school principal, and/ or the PE teacher; local health or sport professionals, such as a social worker; a health promotor; and/or the school doctor; and parents. This "interdisciplinary" team has more knowledge and resources than a working group consisting of school staff only.
2) The working group members collaborate in developing and implementing the KEIGAAF school intervention according to their pupils' needs and community possibilities. Intervention activities do not necessarily have to be completely new initiatives but can be actions to strengthen and combine existing activities. To develop and implement their own KEIGAAF intervention, the working group members meet regularly. During these meetings, their plans and actions are evaluated and improved.

3) The intervention is aimed at increasing children's PA, decreasing sedentariness, and improving nutrition behavior. The intervention is primarily designed to affect health behaviors of 7 to 12 -year-old children.

4) The working groups decide which EBRB/EBRBs they will target primarily, and the extent and order in which this EBRB is targeted during the project period.

The eight working groups are supported by four trained health promotors from Maastricht University or Fontys University of Applied Sciences. The health promotors advise the working groups on effective interventions and discuss study results with them. They meet regularly with each other and with the steering committee to analyze feedback regarding the intervention implementation and exchange best practices. If appropriate, the best practices are adapted and transferred to other working groups. Besides the personal support, each working group receives a small budget (approximately $€ 2500$ for three years) to initiate EBRB-promoting interventions.

\section{Planning}

Schools were recruited in April and May 2016. During the first six months of the next school year (2016-2017), the working groups were formed and local needs defined. To support the working groups in defining their needs, a needs assessment was conducted (see Data collection), consisting of: a) a school scan, b) an environmental scan, and c) working group discussions. Based on local needs, iterative KEIGAAF action plans were developed. Implementation of the KEIGAAF interventions started after the baseline measurements were conducted in March and April 2017. Implementation of the KEIG AAF interventions continues until the final measurements at the end of two years (March and April 2019). The aim is to make sure that the KEIGAAF principles become embedded in the school structure and will be sustained after the final measurements.

\section{Family-based intervention}

A family-based parenting program was implemented stepwise from September 2017. The family-based program (Lifestyle Triple P) mainly targets parents whose 


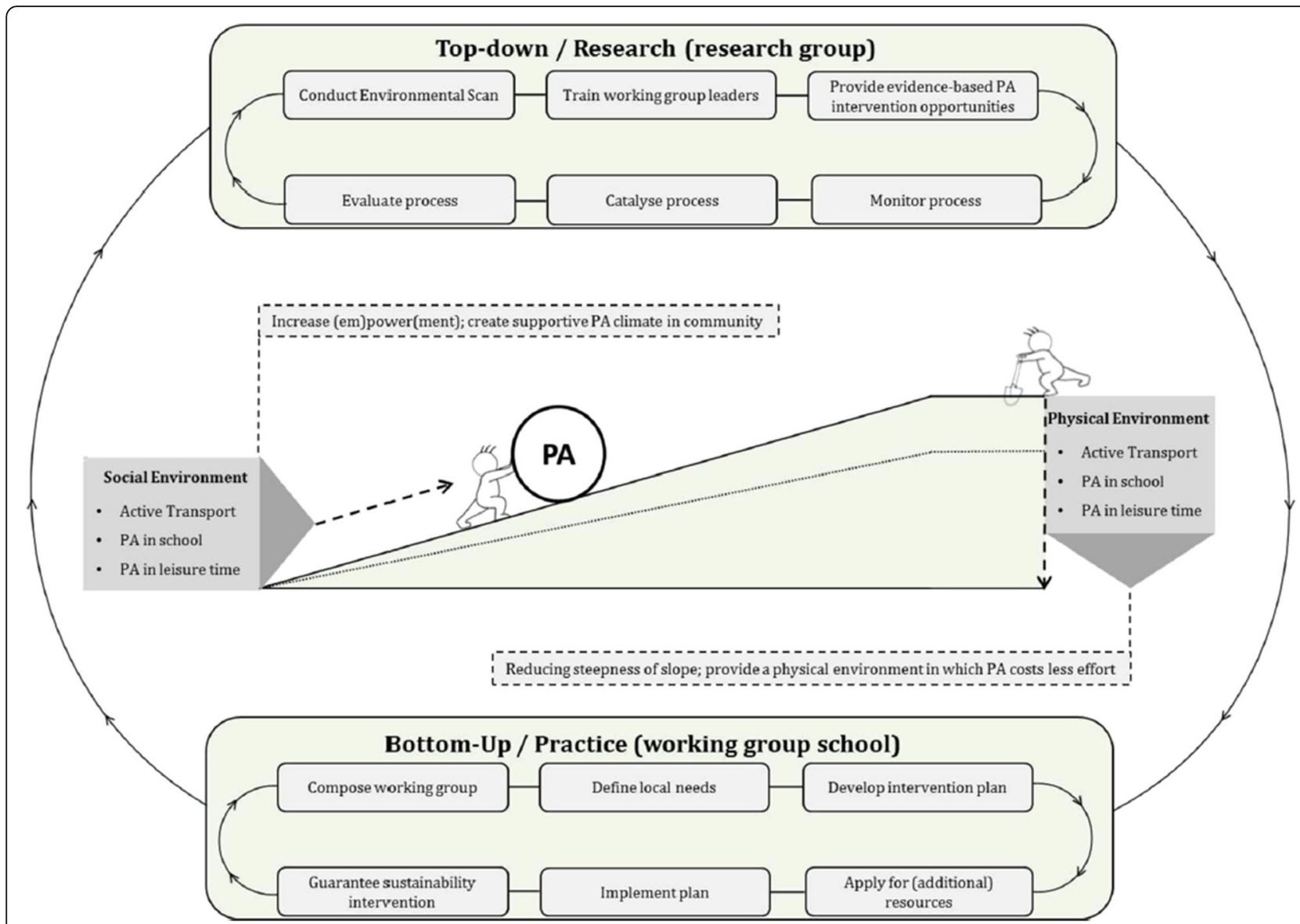

Fig. 2 A visual presentation of the mutual adaptation approach [41]

children are overweight or obese. The aim of the intervention is to improve energy balance-related parenting practices [33, 44]. In eight group sessions and four one-on-one home sessions, Lifestyle Triple P coaches coach parents in positive parenting, nutrition-related parenting practices, and PA-related parenting practices, to support parents in creating a healthy home environment. While the parents attend the Triple P Lifestyle group sessions, their children participate in active fun group play provided by sports students or physical education teachers.

\section{Data collection}

The same data is collected for both the intervention group and the control group. The primary researcher (SV-J) manages the data collection and conducts the measurements in collaboration with trained research assistants. The study is ongoing and data collection has not finished. The data collection is monitored by the Clinical Trial Center Maastricht.

\section{Needs assessment}

At the start of the project (September to November 2016), an environmental scan and a school scan were conducted. For intervention schools, the outcomes of both scans together with the results of working group discussions on local needs served as a basis for the development of the KEIGAAF school intervention by the working groups. The results of the environmental scan and school scan of the control schools were only used for the process evaluation.

Environmental scan An environmental scan, i.e., the SPACE checklist [45], assessed the PA friendliness of the neighborhoods in which the intervention and control schools were located. The SPACE checklist is a validated and adapted version of the Neighborhood Environment Walkability Scale (NEWS) [46]. The checklist was adapted to the Dutch context [45]. The scan was conducted by a researcher and a research assistant at baseline. The same procedures as described by Van Kann and colleagues [41] were applied. The SPACE checklist will also be completed at the end of the project.

School scan At baseline, the schools' principal, teachers, and/or the PE teacher were invited to complete a digital school scan. The school scan was based on an evaluation 
School year 2015-2016

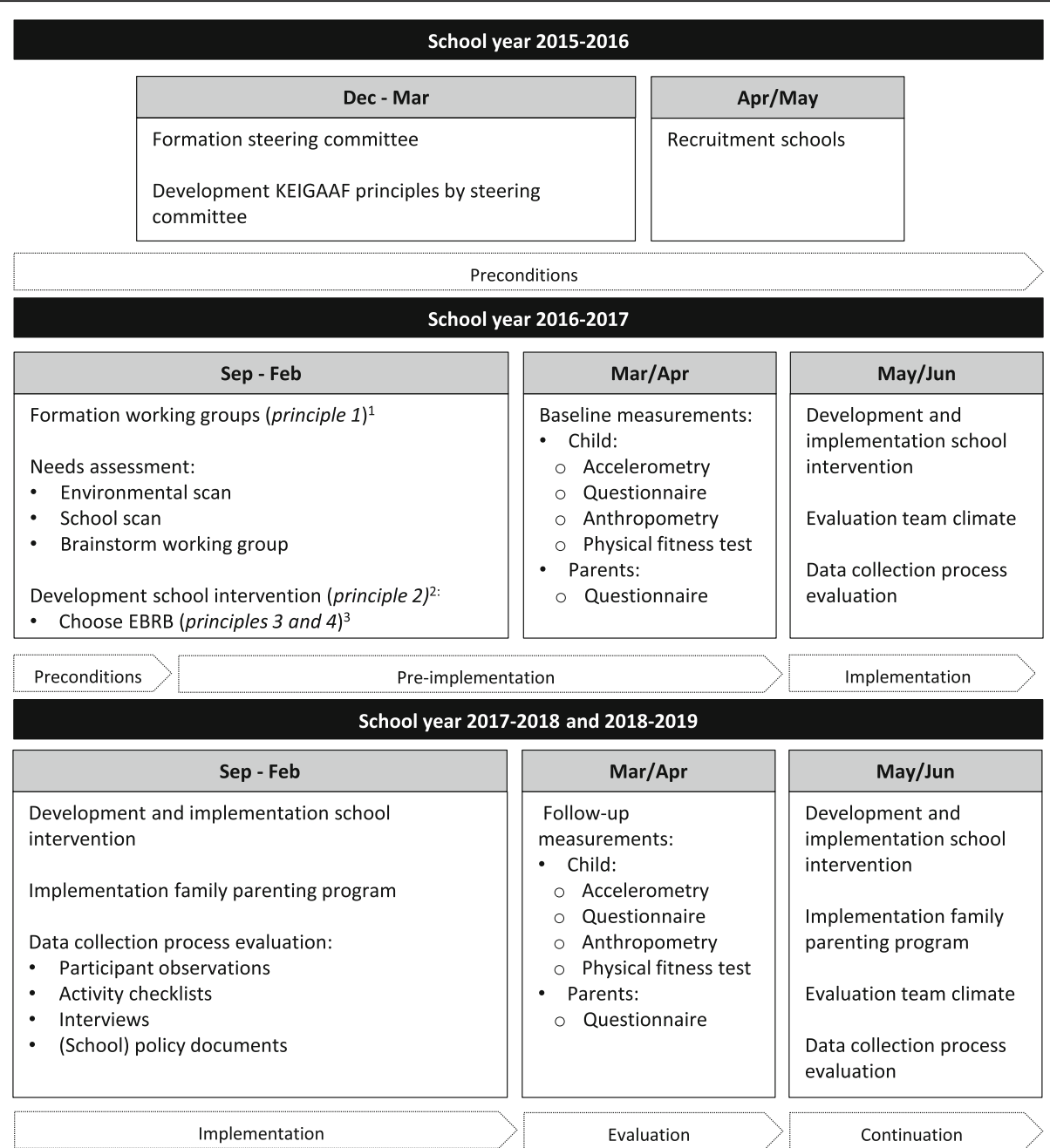

Fig. 3 Timeline of KEIGAAF project. ${ }^{1}$ Principle 1: each school forms a working group, consisting of school staff, local health or sport professionals, a health promotor, and/or the school doctor, and parents. ${ }^{2}$ Principle 2: The working group members develop and implement the KEIGAAF school intervention according to their pupils' needs and community possibilities. ${ }^{3}$ Principle 3 and 4: The intervention's aims are increasing children's PA, decreasing sedentariness and improving nutrition behavior. The working groups decide which energy balance-related behaviors they will target primarily

tool developed for primary schools [47]. This tool had already been in use for five years and was refined annually. This scan assessed the school's activities in the social and physical environment, and school policies, to stimulate PA and healthy nutrition behaviors. Themes are physical education, PA during recess, PA friendliness of schoolyard, PA school activities, active transportation, afterschool PA, PA school policy, teacher and parental involvement in PA promotion at school, nutrition education, healthy nutrition-promoting physical environment, nutrition-promoting activities (including national), nutrition school policy, teacher and parent involvement in healthy nutrition at school. At the beginning of each school year, the school scan is distributed digitally to the schools. The school scan will be completed each year by the same person.

\section{Children}

Child measurements were collected at baseline (March and April of 2017) and will be collected after one year and two years (March and April 2018 \& 2019). Data collection lasts about a week per participating school.

Accelerometry PA and SB are measured via accelerometers (Actigraph GT3X+, Pensacola, FL, USA). The children wear the accelerometers for seven consecutive days. The accelerometers are attached to a belt worn around the child's hip. The children are instructed to wear the accelerometers all day during waking hours but to remove them before performing water-based activities, such as swimming and showering.

Questionnaire Children complete a questionnaire individually in the classroom. The questionnaire was pretested 
among children of the same age attending different schools to ensure that the questions were clear and understandable. The questionnaire assesses demographics, PA at school, sports participation, NB, PA enjoyment, and food, drink, and PA preferences and is for the most part based on validated questionnaires (Table 1).

Anthropometry Anthropometric measurements are taken during a physical education (PE) lesson. Standing height, weight, and waist circumference are measured by researchers or research assistants according to a standardized protocol. Shoes have to be taken off. The children are weighed with a digital weighing scale to the nearest $0.1 \mathrm{~kg}$ (Seca weighing scale 803). Height is measured with a stadiometer to the nearest $0.1 \mathrm{~cm}$ (Seca 213). Weight and height are used to calculate the Body Mass Index (BMI), which is adjusted for age and gender (BMI z-scores) using the values of a Dutch reference population [48]. Waist circumference is measured with a measuring tape to an accuracy of $0.1 \mathrm{~cm}$ (Seca 201). The measuring tape is placed around the umbilicus [49].

Physical fitness test The $15 \mathrm{~m}$ endurance shuttle run test, known as the Progressive Aerobic Cardiovascular Endurance Run (PACER), is used to assess the children's aerobic fitness [50]. The PACER is an item of the EUROFIT test battery [51]. The test is administered during the same PE lesson in which the children's anthropometric measurements are taken. The assessment of the test lasts between 10 and $15 \mathrm{~min}$. The physical fitness test is not conducted during the time that the children wear the accelerometer.

\section{Parents}

Parents are requested to fill in a questionnaire during the one-week measurement period at baseline and at follow-up (March and April 2017, 2018 \& 2019).

Questionnaire The parent questionnaires are handed to the children, and the parents complete them at home. The questionnaires assess demographics, parent's PA pattern routines, PA parenting practices, family health climate, child's NB, anthropometry, and parental school involvement. At follow-up, parents of the intervention schools also receive evaluation questions concerning the KEIGAAF intervention (Table 2).

Questionnaire on family-based intervention The questionnaire related to the family-based intervention is filled in at the start and at the end of the intervention (after three months) by participants of the Lifestyle Triple P intervention. The questionnaire assesses general parenting practices [52], nutrition parenting practices $[53,54]$, and PA parenting practices $[13,55,56]$. Questions to evaluate and improve the program are included in the follow-up questionnaire.

\section{Process evaluation}

An elaborate process evaluation will be conducted in which the processes involved in the implementation of

Table 1 Concepts, number of items, and example question of the child questionnaire

\begin{tabular}{|c|c|c|}
\hline Concept & $\mathrm{N}$ items & Items \\
\hline Demographics & 12 & $\begin{array}{l}\text { Name of school, grade (4th, 5th, 6th), birth month, birth year, gender, home } \\
\text { address, country of birth, country of birth parents, number of siblings }\end{array}$ \\
\hline PA on a school day & 6 & $\begin{array}{l}\text { Television viewing, transportation to school and from school (walking, cycling, } \\
\text { by step/waveboard/skateboard/skates, driven by scooter, driven by car, driven } \\
\text { by bus, other), longest performed activity during recess (running, jumping, } \\
\text { playing, walking, sitting and chatting, standing and chatting, playing inside, } \\
\text { other), activity after school time yesterday (playing outside, sports, active play } \\
\text { inside, low intensity play inside, swimming, music or drama lesson, PC/tablet/ } \\
\text { smartphone use, watching television) }\end{array}$ \\
\hline
\end{tabular}

Sports participation

Nutrition intake on a school day [77]

PA enjoyment [78]

Food and drink preferences [79]

PA preferences [79] tidenone use, watching television)

Member of sports clubs (no, soccer, tennis, dancing, gymnastics/ballet, swimming, horse riding, martial art, basketball, volleyball, handball, hockey, badminton, athletics, cycling, table tennis, korfball, scouts, afterschool PA, other)

Breakfast intake, fruit intake and vegetable intake at school (yes/no), amount of fruit intake $(0.5,1,2,3$ or more pieces), water consumption at school yesterday (yes/no), sugar-sweetened beverages (yes/no), milk drinks (yes/no), energy drinks (yes/no), and sports drinks consumption at school (yes/no), candy (yes/no), cookie (yes/no), and snack consumption (yes/no)

Example: When I am physically active... I enjoy it.

(5-point Likert scale: 1 = totally disagree, $4=$ totally agree, $5=$ don't know)

Examples: Which of the following foods do you prefer more? (fruit or savory snacks) / Which of the following drinks do you prefer more? (soft drink or fruit juice)

Example: Which of the following physical activities do you prefer more? (cycling or watching television) 
Table 2 Concepts, number of items, and example question of the school-based parent questionnaire

\begin{tabular}{|c|c|c|}
\hline Concept & $\mathrm{N}$ items & Items \\
\hline Demographics & 22 & $\begin{array}{l}\text { Name of school child, child's grade (4th, 5th, 6th), gender of child, birth date } \\
\text { of child, birth date of parent, birth date of partner, postal code, relation to } \\
\text { child (mother, stepmother, father, stepfather, guardian, other), country of } \\
\text { birth, highest education level (no education, primary school, pre-vocational } \\
\text { school, secondary education, lower vocational education, higher vocational } \\
\text { education, university), hours per week of paid employment (no paid job, } 16 \\
\text { or less, 17-24, } 25-32 \text {, more than } 32 \text { h), member of sports club (yes/no), family } \\
\text { situation (living together with a partner, single, other) / Partner: relation to } \\
\text { child, country of birth, highest education level, hours per week of paid } \\
\text { employment, member of sports club / number of children (1, 2, 3, } 4 \text { or } \\
\text { more), number of cars (1,2,3 or more). }\end{array}$ \\
\hline
\end{tabular}

Parents' PA transportation $\quad 4$

routines (PATRns) [80]

PA parenting practices [81]

Family health climate [82]

Child's nutrition behavior [77]

Anthropometry

Parental school involvement

KEIGAAF evaluation

(added at follow-up)

only for intervention group
25

Example: If I have to go somewhere nearby, I am always inclined to take the bike or to go on foot. (5-point Likert scale: $1=$ completely disagree, $5=$ completely agree)

Parental logistic support and restrictions on access to sedentary activities. Example: I enroll my child in sports teams and clubs such as soccer, basketball, and dance. (4-point Likert scale: 1 = completely disagree, $4=$ completely agree)

Family climate regarding PA and nutrition.

Example: In our family... a healthy diet plays an important role in our lives. (4-point Likert scale: $1=$ completely disagree, $4=$ completely agree)

Breakfast consumption, fruit intake, vegetable intake, candy intake, cookie intake, snack intake ( 0 to 7 days; amount of portions per day), sugar-sweetened beverages consumption, light soda consumption, fruit juice consumption, sweet milk drinks consumption, milk consumption, water and tea without sugar consumption ( 0 to 7 days; amount of glasses per day)

Weight and height of child, weight and height of parent, weight and height of partner.

Contact with teacher (5-point Likert scale: $1=$ never; $5=$ every week), assisting school with school activities (5-point Likert scale: $1=$ never; $5=$ always), attending parental meeting (5-point Likert scale: $1=$ never; $5=$ always), feeling welcome at school (5-point Likert scale: $1=$ not welcome; 5 =welcome), reading school information ( 5 -point Likert scale: $1=$ never; $5=$ always).

Aware of KEIGAAF (not aware, heard of it, fully aware), general impression of KEIGAAF (5-point Likert scale: 1 = very bad; $5=$ very good), involvement in KEIGAAF (5-point Likert scale: $1=$ very little; $5=$ very much), experiencing changes at school as a result of KEIGAAF (5-point Likert scale: $1=$ very little; $5=$ a lot), experiencing changes at home as a result of KEIGAAF (5-point Likert scale: $1=$ very little; $5=\mathrm{a}$ lot), importance of KEIGAAF (5-point Likert scale: $1=$ very unimportant; $5=$ very important)

KEIGAAF and contextual factors influencing these processes are illuminated. For this, a mixed-methods approach will be used: 1) an activity checklist is filled in throughout the implementation period to gain insight into what is implemented by the different KEIGAAF working groups; 2) a quantitative team climate checklist is filled in at baseline, after one and after two years. This checklist provides information about the climate for innovativeness within a working group [57, 58]; 3) school policy documents are collected, providing information about policies influencing intervention implementation; 4) participant observations of the working groups and semi-structured interviews with working group members are conducted to gain additional knowledge about factors inhibiting or facilitating implementation; and finally, 5) the data of the environmental scan and the school scan provide insight into neighborhood and school factors impeding or facilitating intervention success. Data is collected throughout the implementation period of the combined school- and family-based interventions. The timeline of the KEIGAAF project is shown in Fig. 3.

\section{Data analysis}

Descriptive statistics will be used for baseline data. Accelerometer data will be analyzed using Actilife (Version 6.13.3). To correct for nesting of the data, multilevel regression analyses will be used to analyze it. When studying intervention effects, baseline data will be taken into account as possible confounders. Using forward selection, the random and fixed effects part will be further refined by likelihood ratio tests. Intervention effectiveness will be tested at T1 (after one year) and at T2 (after two years). A two-sided test with a type I error rate of 5\% will be used. Statistical analyses will be conducted using SPSS 24.0 (IBM Corp, USA). 
Quantitative process data will be analyzed with SPSS. Inductive content analysis will be performed to analyze the qualitative process data. Interviews will be transcribed verbatim, and themes and concepts arising from the data will be coded. Outcomes of the process evaluation will be linked to the outcomes of the effectiveness study to clarify the effects on the primary and secondary outcome measures.

\section{Power calculation}

Children's health outcome, i.e., BMI z-score, is the primary outcome measure in this study, while interventions are targeted on more distal health behaviors (EBRBs). EBRBs are used as additional outcome measures and considered as predictors of BMI z-scores. Therefore, baseline measurements of the participants' BMI z-score were used to calculate the power of the study. At baseline, 419 intervention children and 104 control children were included in the study. Children were in grade 4, 5, or 6. In two-level, school-based, cluster randomized trials with BMI z-score as the outcome, the intra-class correlation (ICC) was mostly 0.03 or smaller (e.g., [59-61]). Taking a three-level design into consideration, it is assumed that the ICC ranges from 0.005 for the school level and 0.025 for the class level to an ICC of 0.025 for the school level and an ICC of 0.005 for the class level. For the given sample size, the smallest detectable difference in BMI z-score after two years of intervention ranges between 0.38 and 0.44 when the power is $80 \%$, and between 0.44 and 0.51 when the power is $90 \%$. Using Lipsey's [62] cut-off scores, this indicates a moderate effect. Empirical results show that differences of this size are attainable for combined school- and family-based interventions [63, 64]. Although the effects are moderate, they may lead to clinical significant effects at the population level if they are sustained for several years [65].

\section{Discussion}

In this paper, we present the design of a quasi-experimental study in which we conduct an effect and process evaluation of a context-based, school- and family-based PA and nutrition intervention on children's BMI z-score, their EBRBs, and physical fitness after one and after two years. The focus on two important environmental settings within the child's environment, i.e., school and family, is considered a strength of this intervention. Ecological models, such as the socio-ecological model of Bronfenbrenner, theorize the importance of targeting multiple systems because of the interdependence of these systems [66]. Furthermore, systematic reviews on school-based interventions with parental involvement have shown the importance of targeting both settings $[67,68]$; school-based interventions targeting more home-related factors seem more likely to be effective [68].
The intervention is developed by the intervention schools in collaboration with local professionals and parents, which is in line with the Health Promoting Schools (HPS) framework (also known as Coordinated School Health (CSH) [29, 69]) [70]. The HPS approach has been proven to be effective in improving children's EBRBs $[25,71]$. Because of the combined bottom-up and top-down development of the KEIGAAF intervention, it is expected to be an effective and sustainable version of the HPS: the bottom-up development ensures that the intervention fits the local situation, while top-down decisions (for example, policy decisions taken by the school board) actively stimulate schools to take action, and thereby accelerate the process of actions being taken [72].

In addition to an effect evaluation, an extensive process evaluation will be conducted to provide insights into the processes of designing and implementing the interventions and the role of the context. Few school-based intervention studies have looked at intervention effectiveness and its implementation [73], although this latter information and the link between effectiveness and implementation are important for scaling an intervention and developing future health promotion interventions.

To measure intervention effectiveness, the study has a long duration, and multiple data collection tools are used to measure the different outcomes. The use of accelerometers to measure PA and sedentary behavior is advocated [74] because physical activity questionnaires are subject to under- or over-reporting due to recall bias or social desirability [75]. The questionnaires to measure the other outcome measures are based on validated questionnaires.

This study also has some limitations, e.g., only three schools were recruited as control schools. In general, schools are hesitant to participate in additional projects because of the time pressure experienced. Additionally, recruiting an appropriate control group was difficult: there are numerous national and local efforts to prevent overweight and obesity among children in the Netherlands (e.g., EPODE, healthy schools). It should be noted that the schools located in Maastricht are subject to local health-promoting initiatives. To be able to define the potential effectiveness of the KEIGAAF approach, PA and nutrition-promoting activities implemented in the control schools will also be monitored.

A final limitation is possibly the use of a quasiexperimental study design. A randomized controlled trial is considered the gold standard for studying intervention effectiveness. However, in a project in which there is no strict control over what is implemented and how the system influences implementation, an RCT design is considered inappropriate [76]. Therefore, we consider a quasi-experimental study a good option to study intervention effectiveness. 


\section{Additional file}

Additional file 1: SPIRIT Checklist (DOC $120 \mathrm{~kb}$ )

\author{
Abbreviations \\ BMl: Body mass index; CHS: Comprehensive school health; EBRB: Energy \\ balance-related behaviors; EPODE: Ensemble Prévenons I'Obésité Des Enfants; \\ HPS: Health promoting schools; KEIGAAF: Kansen in Elndhoven voor GezinsAAnpak \\ met Fontys; NB: Nutrition behavior; PA: Physical activity; PE: Physical education; \\ SB: Sedentary behavior; SES: Socio-economic status
}

\section{Acknowledgements}

We are grateful to the teachers, school principals, local professionals, parents, members of the steering committee, and last but not least, the children participating in this study.

\section{Funding}

The present study was funded by Fonds NutsOhra (project number 101.253). Fonds NutsOhra had no role in the writing of this manuscript.

\section{Availability of data and materials}

The questionnaires are available in Dutch from the corresponding author upon request. The data are not yet available.

\section{Authors' contributions}

SV-J drafted and revised the manuscript. SV-J, DVK, and SG designed the study, and SV-J carried out the study. DVK and SG helped draft the manuscript. SK, DVK, and SV initiated the project and obtained funding. SK, SV, and MJ read the manuscript and provided feedback. All authors read and approved the final manuscript.

\section{Ethics approval and consent to participate}

The Medical Ethics Committee of the Maastricht University Medical Center and Maastricht University (METC azM/UM) approved the study (METC163027). After being informed about the study, all participants consented to participate before the start of the study. The parents of the participants signed an informed consent.

\section{Consent for publication}

Not applicable.

\section{Competing interests}

The authors declare that they have no competing interests.

\section{Publisher's Note}

Springer Nature remains neutral with regard to jurisdictional claims in published maps and institutional affiliations.

\section{Author details}

${ }^{1}$ Department of Health Promotion, NUTRIM School of Nutrition and Translational Research in Metabolism, Maastricht University, PO Box 616, Maastricht, The Netherlands. ${ }^{2}$ School of Sport Studies, Fontys University of Applied Sciences, Eindhoven, The Netherlands. ${ }^{3}$ Department of Industrial Design, Eindhoven University of Technology, Eindhoven, The Netherlands. ${ }^{4}$ Academic Collaborative Center for Public Health, Public Health Service South-Limburg, Heerlen, The Netherlands. ${ }^{5}$ Department of Health Services Research, Maastricht University, CAPHRI Care and Public Health Research Institute, Maastricht, The Netherlands.

Received: 5 April 2018 Accepted: 26 June 2018

Published online: 06 July 2018

\section{References}

1. Leefstijlmonitor [https://www.volksgezondheidenzorg.info/onderwerp/sporten-bewegen/cijfers-context/huidige-situatie\#bron\%2D-node-gezondheidsen quête-ge-leefstijlmonitor-lsm] (2015). 05-01-2017.

2. Burghard M, Knitel K, van Oost I, Tremblay MS, Takken T. The Dutch physical activity report card study group: is our youth cycling to health? Results from the Netherlands' 2016 report card on physical activity for children and youth. J Phys Act Health. 2016;13(Suppl 2):S218-24.

3. van Rossum CTM, Fransen HP, Verkaik-Kloosterman J, Buurma-Rethans EJM, Ocke MC. Dutch National Food Consumption Survey 2007-2010: Diet of children and adults aged 7 to 69 years. Bilthoven: RIVM. p. 2011.

4. van de Gaar VM, van Grieken A, Jansen W, Raat H. Children's sugar-sweetened beverages consumption: associations with family and home-related factors, differences within ethnic groups explored. BMC Public Health. 2017;17(1):195.

5. Geurts M, Beukers M, van Rossum C. Consumptie groenten, fruit, vis en een aantal nutriënten opgedeeld naar opleidingsniveau en verstedelijking. Bilthoven: RIVM; 2013.

6. Ruijsbroek A, Wijga AH, Kerkhof M, Koppelman GH, Smit HA, Droomers M. The development of socio-economic health differences in childhood: results of the Dutch longitudinal PIAMA birth cohort. BMC Public Health. 2011;11:225.

7. Van Lenthe FJ, Schrijvers CT, Droomers M, Joung IM, Louwman MJ, Mackenbach JP. Investigating explanations of socio-economic inequalities in health: the Dutch GLOBE study. Eur J Pub Health. 2004;14(1):63-70.

8. Wijtzes Al, Jansen W, Bouthoorn SH, Pot N, Hofman A, Jaddoe WW, Raat H. Social inequalities in young children's sports participation and outdoor play. Int J Behav Nutr Psych Act. 2014;11:155.

9. van Ansem WJ, van Lenthe FJ, Schrijvers CT, Rodenburg G, van de Mheen D. Socio-economic inequalities in children's snack consumption and sugarsweetened beverage consumption: the contribution of home environmental factors. Br J Nutr. 2014;112(3):467-76.

10. Kremers SP, de Bruijn GJ, Visscher TL, van Mechelen W, de Vries NK, Brug J: Environmental influences on energy balance-related behaviors: a dual-process view. Int J Behav Nutr Psych Act. 2006, 3:9.

11. Harrison K, Bost KK, McBride BA, Donovan SM, Grigsby-Toussaint DS, Kim J, Liechty JM, Wiley A, Teran-Garcia M, Jabobsohn GC. Toward a developmental conceptualization of contributors to overweight and obesity in childhood: the six-Cs model. Soc Res Child Dev. 2011;5(1):50-8.

12. Berge JM. A review of familial correlates of child and adolescent obesity: what has the 21 st century taught us so far? Int J Adolesc Med Health. 2009; 21(4):457-83.

13. Gubbels JS, Kremers SP, Stafleu A, de Vries SI, Goldbohm RA, Dagnelie PC, de Vries NK, van Buuren S, Thijs C. Association between parenting practices and children's dietary intake, activity behavior and development of body mass index: the KOALA birth cohort study. Int J Behav Nutr Psych Act. 2011; 8:18.

14. Sleddens EF, Gerards SM, Thiijs C, de Vries NK, Kremers SP. General parenting, childhood overweight and obesity-inducing behaviors: a review. Int J Pediatr Obes. 2011;6(2-2):e12-27.

15. te Velde SJ, Singh A, Chinapaw M, De Bourdeaudhuij I, Jan N, Kovacs E, Bere E, Vik FN, Bringolf-Isler B, Manios Y, et al. Energy balance related behaviour: personal, home- and friend-related factors among schoolchildren in Europe studied in the ENERGY-project. PLOS One. 2014;9(11):e111775.

16. Timperio AF, van Stralen MM, Brug J, Bere E, Chinapaw MJ, De Bourdeaudhuij I, Jan N, Maes L, Manios Y, Moreno LA, et al. Direct and indirect associations between the family physical activity environment and sports participation among 10-12 year-old European children: testing the EnRG framework in the ENERGY project. Int J Behav Nutr Phys Act. 2013;10:15.

17. Verloigne M, Van Lippevelde W, Maes L, Brug J, De Bourdeaudhuij I. Familyand school-based correlates of energy balance-related behaviours in 10-12year-old children: a systematic review within the ENERGY (EuropeaN Energy balance research to prevent excessive weight gain among youth) project. Public Health Nutr. 2012;15(8):1380-95.

18. Verloigne M, Van Lippevelde W, Maes L, Brug J, De Bourdeaudhuij I. Familyand school-based predictors of energy balance-related behaviours in children: a 6-year longitudinal study. Public Health Nutr. 2013;16(2):202-11.

19. Hatfield DP, Chomitz VR. Increasing Children's physical activity during the school day. Curr Obes Rep. 2015;4(2):147-56.

20. Klinker CD, Schipperijn J, Christian H, Kerr J, Ersboll AK, Troelsen J. Using accelerometers and global positioning system devices to assess gender and age differences in children's school, transport, leisure and home based physical activity. Int J Behav Nutr Psych Act. 2014;11:8.

21. van Stralen MM, Yildirim M, Wulp A, te Velde SJ, Verloigne M, Doessegger A, Androutsos O, Kovacs E, Brug J, Chinapaw MJ. Measured sedentary time and physical activity during the school day of European 10- to 12-year-old children: the ENERGY project. J Sci Med Sport. 2014;17(2):201-6.

22. van Ansem WJ, Schrijvers CT, Rodenburg G, Schuit AJ, van de Mheen D. School food policy at Dutch primary schools: room for improvement? 
Cross-sectional findings from the INPACT study. BMC Public Health. 2013;13:339.

23. Wechsler H, Devereaux RS, Davis M, Collins J. Using the school environment to promote physical activity and healthy eating. Prev Med. 2000;31:S121-37.

24. Lewallen TC, Hunt H, Potts-Datema W, Zaza S, Giles W. The whole school, whole community, whole child model: a new approach for improving educational attainment and healthy development for students. J Sch Health. 2015;85(11):729-39.

25. Langford R, Bonell CP, Jones HE, Pouliou T, Murphy SM, Waters E, Komro KA, Gibbs LF, Magnus D, Campbell R. The WHO health promoting school framework for improving the health and well-being of students and their academic achievement. Cochrane Database of Syst Rev. 2014;4:Cd008958.

26. Patton MQ. Developmental evaluation: applying complexity concepts to enhance innovation and use. New York: The Guilford Press; 2011.

27. Keshavarz N, Nutbeam D, Rowling L, Khavarpour F. Schools as social complex adaptive systems: a new way to understand the challenges of introducing the health promoting schools concept. Soc Sci Med. 2010; 70(10):1467-74.

28. Mclsaac JL, Hernandez KJ, Kirk SF, Curran JA. Interventions to support system-level implementation of health promoting schools: a scoping review. Int J Environ Res Public Health. 2016;13(2):200.

29. Storey KE, Montemurro G, Flynn J, Schwartz M, Wright E, Osler J, Veugelers PJ, Roberts E. Essential conditions for the implementation of comprehensive school health to achieve changes in school culture and improvements in health behaviours of students. BMC Public Health. 2016;16(1):1133.

30. Langford R, Bonell C, Jones H, Campbell R. Obesity prevention and the health promoting schools framework: essential components and barriers to success. Int J Behav Nutr Psych Act. 2015;12:15.

31. Mclsaac JL, Mumtaz Z, Veugelers PJ, Kirk SF. Providing context to the implementation of health promoting schools: a case study. Eval Program Plann. 2015;53:65-71.

32. Buchanan $\mathrm{DR}$, Miller FG, Wallerstein $\mathrm{N}$. Ethical issues in community-based participatory research: balancing rigorous research with community participation in community intervention studies. Prog Community Health Partnersh. 2007;1 (2):153-60.

33. Gerards SM, Dagnelie PC, Gubbels JS, van Buuren S, Hamers FJ, Jansen MW, van der Goot OH, de Vries NK, Sanders MR, Kremers SP. The effectiveness of lifestyle triple $\mathrm{P}$ in the Netherlands: a randomized controlled trial. PLoS One. 2015;10(4):e0122240

34. Gerards SM, Sleddens EF, Dagnelie PC, de Vries NK, Kremers SP. Interventions addressing general parenting to prevent or treat childhood obesity. Int J Pediatr Obes. 2011;6(2-2):e28-45.

35. Vander Ploeg KA, Maximova K, McGavock J, Davis W, Veugelers P. Do school-based physical activity interventions increase or reduce inequalities in health? Soc Sci Med. 2014;112:80-7.

36. Amini M, Djazayery A, Majdzadeh R, Taghdisi MH, Jazayeri S. Effect of school-based interventions to control childhood obesity: a review of reviews. Int J Prev Med. 2015;6:68.

37. Semenza JC, Suk J, Manissero D. Intervening on high-risk or vulnerable populations? Am J Public Health. 2008:98(8):1351-2. author reply 1352

38. Nishtar S, Gluckman P, Armstrong T. Ending childhood obesity: a time for action. Lancet. 2016;387(10021):825-7.

39. Van Kann DHH, Kremers SP, de Vries NK, de Vries SI, Jansen MW. The effect of a school-centered multicomponent intervention on daily physical activity and sedentary behavior in primary school children: the active living study. Prev Med. 2016;89:64-9.

40. Kok MO, Vaandrager L, Bal R, Schuit J. Practitioner opinions on health promotion interventions that work: opening the 'black box' of a linear evidence-based approach. Soc Sci Med. 2012;74(5):715-23.

41. Van Kann DHH, Jansen MWJ, de Vries NK, de Vries SI, Kremers SPJ. Active living: design of a longitudinal, quasi-experimental physical activity intervention for primary school children. BMC Public Health. 2015;15:1315-25.

42. McLaughlin MW. The Rand agent study revisited: macro perspectives and micro realities. Educ Res. 1990;19(9):11-6.

43. Hawe P, Shiell A, Riley T. Theorising interventions as events in systems. Am J Community Psychol. 2009:43(3-4):267-76.

44. West F, Sanders MR, Cleghorn GJ, Davies PS. Randomised clinical trial of a family-based lifestyle intervention for childhood obesity involving parents as the exclusive agents of change. Behav Res Ther. 2010;48(12):1170-9.

45. de Vries SI, Hopman-Rock M, Bakker I, Hirasing RA, van Mechelen W. Built environmental correlates of walking and cycling in Dutch urban children: results from the SPACE study. Int J Environ Res Public Health. 2010;7(5): 2309-24.

46. Saelens BE, Sallis JF, Black JB, Chen D. Neighborhood-based differences in physical activity: an environment scale evaluation. Am J Public Health. 2003; 93(9):1552-8.

47. Slingerland M, Vervoort J, Verheijen S. Brabantse Basisscholen in Beweging: Twee vliegen in 1 klap! In: Tv A, editor. Thomas Bulletin, vol. 73; 2013. p. 39-41.

48. Schonbeck Y, Talma H, van Dommelen P, Bakker B, Buitendijk SE, Hirasing RA, van Buuren S. Increase in prevalence of overweight in Dutch children and adolescents: a comparison of nationwide growth studies in 1980, 1997 and 2009. PLoS One. 2011;6(11):e27608.

49. WHO. Waist Circumference and Waist-Hip Ratio: Report of a WHO Expert Consultation. Geneva: World Health Organisation; 2008.

50. Mahar MT, Guerieri AM, Hanna MS, Kemble CD. Estimation of aerobic fitness from 20-m multistage shuttle run test performance. Am J Prev Med. 2011; 41(4 Suppl 2):S117-23.

51. Van Mechelen W, Van Lier WH, Van Hlobil H, Crolla I, Kemper HCG. Eurofit : handleiding met referentieschalen voor 12- tot en met 16-jarige jongens en meisjes in Nederland. Haarlem: Uitgeverii de Vrieseborch; 1991.

52. Sleddens EFC, O'Connor TM, Watson KB, Hughes SO, Power TG, Thijs C, De Vries N, Kremers SPJ. Development of the comprehensive general parenting questionnaire for caregivers of 5-13 year olds. Int I Behav Nutr Psych Act. 2014;11:15.

53. Gevers DWM, Kremers SP, de Vries NK, van Assema P: Development of the Comprehensive Snack Parenting Questionnaire: Test-retest reliability and discriminative value of constructs. Dissertation. Maastricht: Maastricht University; 2016.

54. Musher-Eizenman D, Holub S. Comprehensive feeding practices questionnaire: validation of a new measure of parental feeding practices. J Pediatr Psychol. 2007:32(8):960-72.

55. O'Connor TM, Cerin E, Hughes SO, Robles J, Thompson DI, Mendoza JA, Baranowski T, Lee RE. Psychometrics of the preschooler physical activity parenting practices instrument among a Latino sample. Int J Behav Nutr Phys Act. 2014;11:3.

56. Gattshall ML, Shoup JA, Marshall JA, Crane LA, Estabrooks PA. Validation of a survey instrument to assess home environments for physical activity and healthy eating in overweight children. Int J Behav Nutr Phys Act. 2008;5:3.

57. Strating MM, Nieboer AP. Psychometric test of the team climate inventoryshort version investigated in Dutch quality improvement teams. BMC Health Serv Res. 2009:9:126.

58. Fleuren MAH, Paulussen TGWM, Van Dommelen S, Van Buuren S. Towards a measurement for determinants of innovations. Int J Qual Health Care. 2014; 26(5):501-10.

59. Amorim LD, Bangdiwala SI, McMurray RG, Creighton D, Harrell J. Intraclass correlations among physiologic measures in children and adolescents. Nurs Res. 2007;56(5):355-60.

60. Gray HL, Burgermaster M, Tipton E, Contento IR, Koch PA, Di Noia J. Intraclass correlation coefficients for obesity indicators and energy balance-related behaviors among new York City public elementary schools. Health Educ Behav. 2016;43(2):172-81.

61. Johnson BA, Kremer PJ, Swinburn BA, de Silva-Sanigorski AM. Multilevel analysis of the be active eat well intervention: environmental and behavioural influences on reductions in child obesity risk. Int J Obes. 2012;36(7):901-7.

62. Lipsey MW. Design sensitivity: statistical power for experimental research. Thousand Oaks, CA: Sage Publications; 1990

63. Jiang J, Xia X, Greiner T, Wu G, Lian G, Rosenqvist U. The effects of a 3-year obesity intervention in schoolchildren in Beijing. Child Care Health Dev. 2007;33(5):641-6.

64. Manios Y, Moschandreas J, Hatzis C, Kafatos A. Evaluation of a health and nutrition education program in primary school children of Crete over a three-year period. Prev Med. 1999:28(2):149-59.

65. Waters E, de Silva-Sanigorski A, Hall BJ, Brown T, Campbell KJ, Gao Y, Armstrong R, Prosser L, Summerbell CD. Interventions for preventing obesity in children. Cochrane Database of Sys Rev. 2011;12:Cd001871.

66. Bronfenbrenner $\mathrm{U}$. The ecology of human development: experiments by nature and design. Cambridge, MA: Harvard University Press; 1979.

67. Hendrie GA, Brindal E, Corsini N, Gardner C, Baird D, Golley RK. Combined home and school obesity prevention interventions for children: what behavior change strategies and intervention characteristics are associated with effectiveness? Health Educ Behav. 2012;39(2):159-71. 
68. Van Lippevelde W, Verloigne M, De Bourdeaudhuij I, Brug J, Bjelland M, Lien $\mathrm{N}$, Maes L. Does parental involvement make a difference in school-based nutrition and physical activity interventions? A systematic review of randomized controlled trials. Int J Public Health. 2012:57(4):673-8.

69. Veugelers PJ, Schwartz ME. Comprehensive school health in Canada. Can J Public Health. 2010;101(Suppl 2):S5-8.

70. Macnab AJ, Gagnon FA, Stewart-Brown S, Sowden A. Health promoting schools: consensus, strategies and potential Health Educ. 1999;114(3)

71. Fung C, Kuhle S, Lu C, Purcell M, Schwartz M, Storey K, Veugelers PJ. From "best practice" to "next practice": the effectiveness of school-based health promotion in improving healthy eating and physical activity and preventing childhood obesity. Int J Behav Nutr Psych Act Behavior. 2012;9:27.

72. McLaughlin MW. Learning from experience: lessons from policy implementation. Educ Eval Policy Anal. 1987;9(2):171-8.

73. Naylor PJ, Nettlefold L, Race D, Hoy C, Ashe MC, Wharf Higgins J, McKay HA Implementation of school based physical activity interventions: a systematic review. Prev Med. 2015;72:95-115.

74. van Sluijs EM, Kriemler S. Reflections on physical activity intervention research in young people - dos, don'ts, and critical thoughts. Int J Behav Nutr Psych Act. 2016;13:25.

75. Chinapaw MJ, Mokkink LB, van Poppel MN, van Mechelen W, Terwee CB. Physical activity questionnaires for youth: a systematic review of measurement properties. Sports Med. 2010;40(7):539-63.

76. Macnab AJ, Gagnon FA, Stewart-Brown S, Sowden A. Health promoting schools: consensus, strategies and potential Health Educ. 1999;114(3):1.

77. Monitor Gezondheid [www monitorgezondheid nl] (2005). 17-11-2016.

78. Kendzierski D, DeCarlo KJ. Physical activity enjoyment scale: two validation studies. J Sport Exerc Psychol. 1991;13(1):50-64.

79. Rodenburg G, Oenema A, Pasma M, Kremers SP, van de Mheen D. Clustering of food and activity preferences in primary school children. Appetite. 2013; 60(1):123-32.

80. Van Kann DHH, Kremers SPJ, de Vries SI, de Vries NK, Jansen MWJ. Parental active transportation routines (PATRns) as a moderator of the association between neighborhood characteristics and parental influences and active school transportation. Environ Behav. 2016;48(7):946-65.

81. Davison KK, Li K, Baskin ML, Cox T, Affuso O. Measuring parental support for children's physical activity in white and African American parents: the activity support scale for multiple groups (ACTS-MG). Prev Med. 2011;52(1):39-43.

82. Niermann C, Krapf F, Renner B, Reiner M, Woll A. Family health climate scale (FHC-scale): development and validation. Int J Behav Nutr Psych Act. 2014; 11(1):30.

\section{Ready to submit your research? Choose BMC and benefit from:}

- fast, convenient online submission

- thorough peer review by experienced researchers in your field

- rapid publication on acceptance

- support for research data, including large and complex data types

- gold Open Access which fosters wider collaboration and increased citations - maximum visibility for your research: over $100 \mathrm{M}$ website views per year

At BMC, research is always in progress.

Learn more biomedcentral.com/submissions 